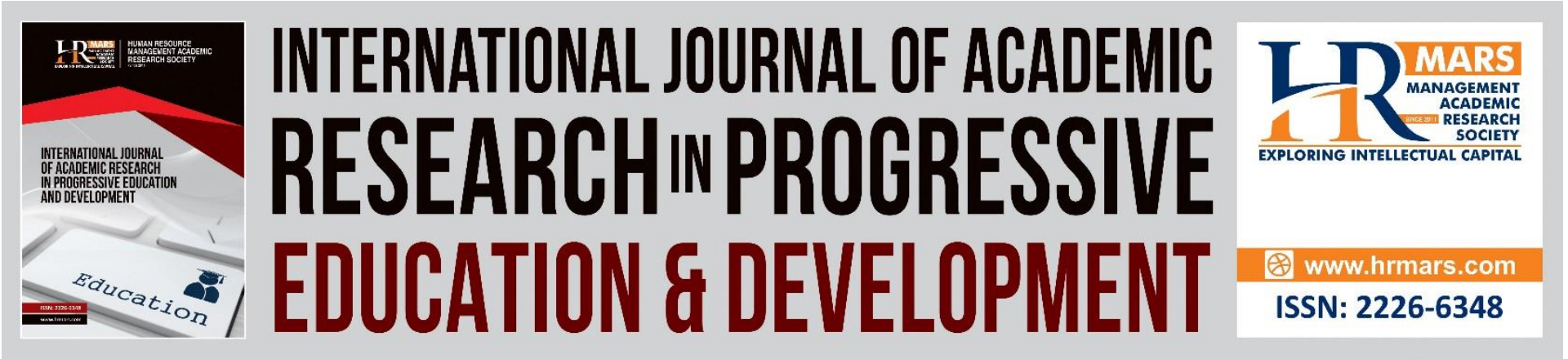

\title{
An Account of Approaches to Language Testing
}

\author{
Ahmed Mohammed S. Alduais
}

To Link this Article: http://dx.doi.org/10.6007/IJARPED/v1-i4/11962

DOI: 10.6007/IJARPED/v1-i4/11962

Received: 12 September 2012, Revised: 13 October 2012, Accepted: 29 October 2012

Published Online: 21 November 2012

In-Text Citation: (Alduais, 2012)

To Cite this Article: Alduais, A. M. S. (2012). An Account of Approaches to Language Testing. International Journal of Academic Research in Progressive Education and Development, 1(4), 1-6.

Copyright: @ 2012 The Author(s)

Published by Human Resource Management Academic Research Society (www.hrmars.com)

This article is published under the Creative Commons Attribution (CC BY 4.0) license. Anyone may reproduce, distribute, translate and create derivative works of this article (for both commercial and non-commercial purposes), subject to full attribution to the original publication and authors. The full terms of this license may be seen at: http://creativecommons.org/licences/by/4.0/legalcode

Vol. 1(4) 2012, Pg. 1 - 6

http://hrmars.com/index.php/pages/detail/IJARPED

JOURNAL HOMEPAGE

Full Terms \& Conditions of access and use can be found at http://hrmars.com/index.php/pages/detail/publication-ethics 


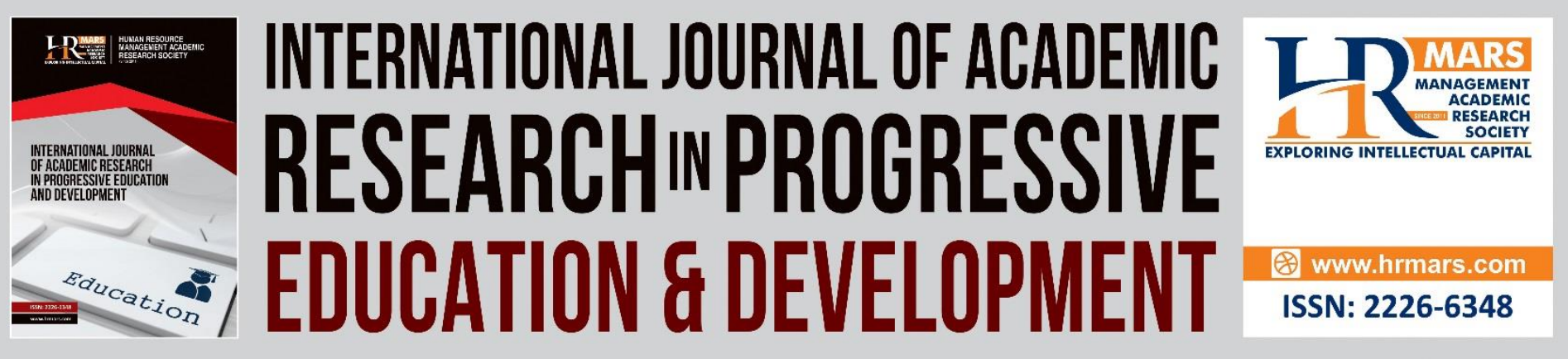

\title{
An Account of Approaches to Language Testing
}

\author{
Ahmed Mohammed S. Alduais \\ Department of English Language, King Saud University, Kingdom of Saudi Arabia \\ Email: ibnalduais@yahoo.com
}

\begin{abstract}
You design your test, I design my test and every teacher else designs his/her own test in the way he/she likes it ignoring the fact that our tests should be based on certain characteristics. This argument, however, includes issues such as what to test, how to test and on what bases you design a test: have been all discussed in this paper with the help of accounting briefly for four approaches to language testing. Thus, the four approaches (translation approach, psychometric-structuralists approach, integrative approach and communicative approach) have been accounted for comparatively and contrastively.
\end{abstract}

Keywords: Language Testing, Translation Approach, Psychometric-Structuralists Approach, Integrative Approach, Communicative Approach, Test Design.

\section{Introduction}

Language testing as a major part in language teaching and language learning has its own history in terms of supporting theories and unsupportive theories. Like other fields in language study, other fields have greatly influenced language testing, namely, translation approach theory, psychology, educational psychology, structural linguistics, sociology, closure theory (Gestalt), divisibility hypothesis, statistics, etc. For that matter, one can infer that language testing as a field in Applied Linguistics has been gradually developed influenced by all the above theories and fields in addition to the attempts of both linguists and applied linguists to push it forward and forward to appear in the picture it has today. Due to this, four major approaches to language testing have appeared, namely: 1) essay translation approach (prescientific era), 2) psychometric-structuralists approach, 3) integrative approach (pragmatic) and 4) communicative approach. Actually, all the above mentioned approaches are different from one another, yet share some similarities.

\section{Comparing and Contrasting Language Testing Approaches}

Nearly, from the early 1900s onward all tests were designed at that age were generally considered as (pre-scientific), because they were written and designed intuitively without following any kind of procedures and principles. For that matter, followers of such method were categorized under the (pre-scientific era). Instead, it was called the essay translation approach as a result of its influence by the essay translation approach. In other words, the focus of the tests was on essay writing, translation, grammar structures mainly form and phonetics (form also). Moreover, proponents of such an approach were to some extent bias to culture and literature involvement in their tests. At all rates, tests designed in such a period 
were described as intuitive, subjective, impressionistic yet impressionistically evaluated tests and unspecific, (Madsen, 1983; McNamara, 2000; McNamara \& Roever (unknown) and Weir, 2005).

As a result of the failure of the above mentioned approach to achieve the purposes of both language teachers and learners, yet and more importantly with the rise of many sciences and marrying between them, some fields have become more powerful. For instance, language testing has been greatly influenced by psychology and structural linguistics and the result was what is being called in nowadays the scientific era of language testing or more accurately the psychometric-structuralists approach to language testing. Therefore, the 1950s has come with a new approach to language testing led by both structural linguists (like Lado and his theory in his proposed field Contrastive Analysis) and psychologists, (Madsen, 1983; McNamara, 2000; McNamara \& Roever (unknown) and Weir, 2005). .

Once again and compared with the translation approach theory, the psychometricstructuralists approach was described as scientific, led by principles and procedures, its tests are to some extent valid and reliable (influenced by statistics). Linguistically, followers (proponents) of this approach, yet opponents of the earlier approach, were focusing on testees' knowledge of the grammar system, vocabulary, and sound system. In other words and with reference to (McNamara, 2000: p. 14), there was a 'tendency to atomize and decontextualize the knowledge to be tested'. For that matter, what is being known as discretepoint-tests, were followed by nearly all proponents of such an approach when designing their tests. Needless to say, according to the structuralists' theory, language is both learned and acquired as systematic habits (influenced by behaviourism: a school in psychology led by Skinner and Pavlov). On the basis of this, each language skill (receptive: listening and reading, productive: speaking and writing), yet each language sub-skill or component: (sound system, grammar structures and vocabulary), must be tested separately so that each skill or sub-skill can be evaluated properly, (Madsen, 1983; McNamara, 2000; McNamara \& Roever (unknown) and Weir, 2005).

While the tests which were designed on the basis of the translation theory approach were described as subjective, and impressionistic; the tests in the psychometric-structuralists era were and still being described as objective, statistics-based-exams; that is, nonimpressionistic, (Madsen, 1983; McNamara, 2000,;McNamara \& Roever (unknown) and Weir, 2005).

On the hand, every approach has its heyday, yet its unpopular-day and this applied to the psychometric-structuralists approach just like it applied to the earlier approach and may be to the other two approaches. Actually, the opponents of this approach have criticized it for its inability to achieve communication which is a major aim of learning and acquiring any language, (Madsen, 1983; McNamara, 2000; McNamara \& Roever (unknown) and Weir, 2005).

Because of the above mentioned reason, a new school for language testing has come to life, namely called the pragmatics or integrative approach to language testing. From among the major proponents of this approach is Oller who has introduced his influential hypothesis (Unitary Competence Hypothesis), (Madsen, 1983; McNamara, 2000; McNamara \& Roever (unknown) and Weir, 2005). 
Contrastively, the tests which were designed on the basis of this approach were described as holistic, integrative, pragmatic, sociological, subjective, yet and more importantly were characterized by two features: 1) assessing practical language skills of foreign learners who wish to be enrolled in the English speaking community universities-say UK and USA, and 2) both skills and sub-skills of language were integrated to achieve the communication purpose which was not achieved by the earlier approaches especially the psychometric-structuralists approach, (Madsen, 1983; McNamara, 2000; McNamara \& Roever (unknown) and Weir, 2005).

Moreover, for the proponents of the integrative approach and pragmatic tests, the focus was on meaning, context, at least two or more skills and sub-skills must go together (tested together), involvement of language functions but not their use, common use of dictation and cloze procedure tests, oral interviews and finally composition writing. Of course, it should be noted the cloze procedure tests were and are common for testing reading comprehension, but for Oller such type of test could be used where in two or more skills/sub-skills are integrated. Again, it should be noted that the cloze procedure test was by itself influenced by the Gestalt's theory of closure closing gaps in patterns sub-consciously, (Madsen, 1983; McNamara, 2000; McNamara et al., 2005).

As the time has passed, it has been discovered by the opponents of the integrative and pragmatic tests approach that such an approach is not to a great extent different from the psychometric-structuralists approach, because no clear-short-cuts were drawn regarding testing communicative skills of language. One more drawback of this approach is its unreliability and invalidity in the case of translation tests, because many skills and sub-skills are required not only from the target language but also from the native tongue language, that is, the source language, (Madsen, 1983; McNamara, 2000; McNamara et al., 2005).

Consequently, a new approach for language testing has show up, namely called the communicative approach to language testing.

Like the above three discussed approaches to language testing, this approach has been also influenced by a theory, namely communicative competence theory (Hymes' theory). According to this theory and approach, knowing language is more than knowing its rules, (Madsen, 1983; McNamara, 2000; McNamara et al., 2005).

Above all, tests which were designed following this approach were characterized by two features: 1) learners are assessed with the use of performance tests on the basis of communication acts they perform be it receptive or productive, 2) social roles must be integrated in any test, (Madsen, 1983; McNamara, 2000; McNamara et al., 2005).

One clear area where in the psychometric-structuralists, integrative and communicative approaches can be contrasted is that in the former ones, language is interpreted psychologically as an internal psychological phenomenon, and in the latter one (communicative), language is interpreted sociologically as an external phenomenon. Yet, in both approaches language is a means of communication and the major aim of tests is testing the learners' ability to communicate effectively; that is to use productively what they have learned receptively [prospectively]. 
Furthermore and in contrast, according to this approach, the tests are being evaluated in terms of language use rather than language form as in the translation approach. Once again, while dictation is only encouraged by the proponents of both the translation approach and integrative approach, in this approach it is highly encouraged. On the hand, in the case of the psychometric-structuralists approach it was being criticized and discarded, (Madsen, 1983; McNamara, 2000; McNamara et al., 2005; Hinkel, 2005).

The last area where the last approach to language testing can be contrasted to the other approaches mainly the second one is that in such an approach a tester must take into consideration-say in test for specific purposes that a test for students of medicine in an Arab country must be different for the student of medicine in Japan or China; that is, culture must be taken into consideration. Of course, this last point in addition to stressing on test specifications on the basis of the needs of the learners are two major advantages and areas of power for the communicative approach. In other words, for other approaches especially the psychometric-structuralists approach, a test can be used globally regardless of the culture differences of one country from another.

Finally it important to note that some other theorists and experts in language field mainly language testing have tried to introduce a new approach which serves both teaching and learning, not biased to any approach, yet this approach by itself was to some extent biased to the communicative approach, namely influenced by sociology. Thus, Bachman is a clear example and a proponent of such an approach, (Bachman, 1990 and Bachman \& Palmer 1996).

Needless to say, no matter what kind of approach is followed since it achieves a positive and useful backwash-washback to both language teaching and language learning, (Cheng, Watanabe \& Curtis, 2004; Hughes, 1989).

\section{Conclusion}

To sum up, four major approaches to language testing have been introduced comparatively and contrastively: 1 ) the pre-scientific era (no specific rules and procedures, intuitive testing, 2) Scientific psychometric phase (certain principles and procedures should be followed, this approach was developed by psychologists and it has some characteristics including: a) deciding on the tested area (reading, writing, sound, etc.), b) use of objective itemized tests (multiple choices questions), c) focus on specific language elements or skills, d) the use of statistics to see the average (validity and reliability of the designed test), 3 ) integrative/ holistic or pragmatic approach: it doesn't test language and from among the famous people of this approach is Oller. According to him test should be general (speaking and listening) for example must go together because they are interrelated (discrete tests must be used). Oller mentioned (dedication) as an example for such a kind of tests, it combines many skills whish are tested at the same time. Actually this phase (approach) was replaced by the communicative phase. Oller has also suggested (Cloze test), a test where in some items are deleted and students are asked to attempt to fill the blanks and reach the deleted items. However, such a kind of test is used for reading comprehension in nowadays, but for Oller it is an integrative test. He also adds dialogues which are the closest to his introduced approach as they combine language subskills (components), and finally 4) communication Testing approach: there is an emphasis on communicative competence (use $=$ appropriateness) and (usage $=$ grammar). Actually, a test in 
this approach would combine between pure and hybrid tests, the ability to use language for communicative purposes, focusing on LANGUGAE and not on KNOWELDGE of language.

\section{Acknowledgement}

The author would like to greatly thank Dr. Mahmoud Saleh, the professor of Applied Linguistics at King Saud University, Riyadh, Saudi Arabia, for his valuable comments on this paper.

\section{References}

Bachman, L. F. (1990). Fundemental Consderations in Language Testing . Oxford : Oxford University Press.

Bachman, L. F., \& Palmer, A. S. (1996). Language Testing in Practice . Oxford : Oxford University Press.

Cheng, L., Watanabe, Y., \& Curtis, A. (Ed.). (2004). WASHBACK IN LANGUAGE TESTING: Research Contexts and Methods. Mahwah, New Jersey London, LAWRENCE ERLBAUM ASSOCIATES, PUBLISHERS.

Heaton, J. B. (1990). Longman Handbooks for Language Teachers: Writing English Language Tests (New ed.). London and New York: Longman Group UK Ltd.

Hinkel, E. (Ed.). (2005). Handbook of Research in Second Language Teaching and Learning. Mahwah, New Jersey and London: Lawrence Erlbaum Assoicates, Publishers .

Hughes, A. (1989). Testing for Language Teachers . Cambridge : Cambridge University Press. Madsen, H. S. (1983). Techinques in Testing . Oxford: Oxford University Press.

McNamara, T. (2000). Oxford Introductions to Language Study: Language Testing. (H. G. Widdowson, Ed.) Oxford, New York: Oxford University Press.

Weir, C. J. (2005). Language Testing and Validation: An Evidence-based Approach. PALGRAVE MACMILLAN. 